\title{
A educação do campo e os desafios para uma educação infantil do campo: uma trajetória nas/das leis e nas/das lutas
}

Thiago Roniere Rebouças Tavares ${ }^{1}$, Geralda Maria de Bem²

\section{Resumo}

Este texto tem como objetivo traçar o percurso que efetivou a proposta de uma educação infantil do campo. Desta forma, lançamos mão de apontamentos sobre marcos históricos que indicam essa trajetória, desde a ausência do processo educacional no espaço agrário, passando pela proposta de educação rural e as críticas a ela, o debate para elaboração de uma educação do campo e sua especificidade pedagógica infantil. Utilizamos como procedimento metodológico a pesquisa bibliográfica, estudando os autores: Caldart (2008, 1997), Fernandes (1999, 2006), Silva (2012), bem como as Diretrizes Operacionais para Educação Básica nas escolas do campo, dentre outros documentos e autores.

\section{Palavras-chave}

Educação Infantil do Campo. Legislação. Educação Rural. Lei de Diretrizes e Bases.

1. Doutorando em Geografia na Universidade Federal do Rio de Janeiro, Brasil; professor substituto na mesma instituição. E-mail: thiagoroniere@gmail.com.

2. Mestra em Ensino pela Universidade do Estado do Rio Grande do Norte, Brasil; professora da rede municipal de ensino de Pau dos Ferros, Rio Grande do Norte, Brasil. E-mail: geraldabem@hotmail.com. 


\title{
Countryside education and the challenges for a countryside education for children: a trajectory to/by laws and to/by fights
}

Thiago Roniere Rebouças Tavares*, Geralda Maria de Bem**

\begin{abstract}
The purpose of this text is to outline the course that has made the proposal for Countryside Education for Children. In this way, we draw attention to historical milestones that indicate this trajectory, from the absence of the educational process in the agrarian space, through the offer of rural education, its critics, the debate to elaborate a Field Education and its children's pedagogical specificity. We used as methodological procedure the bibliographic research, studying the authors: Caldart (2008, 1997), Fernandes (1999, 2006) Silva (2012), as well as the Operational Guidelines for Basic Education in the Field Schools, among other documents and authors.
\end{abstract}

\section{Keywords}

Geography Teaching. Infantile Education of the Field. Legislation.

\footnotetext{
* PhD student in Geography, Federal University of Rio de Janeiro, State of Rio de Janeiro, Brazil; substitute professor at the same institution. E-mail: thiagoroniere@gmail.com.

** Master of Teaching, University of the State of Rio Grande do Norte, Brazil; teacher at the municipal education system at Pau dos Ferros, State of Rio Grande do Norte, Brazil. E-mail: geraldabem@hotmail.com.
} 


\section{Introdução}

Este texto tem como objetivo traçar o percurso que efetivou a proposta de uma educação infantil do campo. Lançamos mão de apontamentos e marcos históricos que indicam essa trajetória, desde a ausência do processo educacional no espaço agrário, passando pela proposta de educação rural e as críticas a ela, o debate para elaboração de uma educação do campo e sua especificidade pedagógica infantil. Para isso, consideramos a postura ativa dos sujeitos presentes nesse debate, sejam eles organizados coletivamente em movimentos sociais, assim como no papel desempenhado por educadores e pesquisadores engajados no debate e na defesa para efetivação da proposta em tela.

Cabe justificar que a escolha temática desse trabalho partiu, dentre as várias referências que surgiram no texto, de pesquisas bibliográficas dos autores: Caldart (2008, 1997), que vem refletindo sobre a educação do campo levando em consideração a história e a cultura dos povos do campo; Silva (2012), que tem abordado o retrato sociológico das infâncias do campo, ressaltando as vivências das crianças em contextos rurais; dentre outros que se debruçaram na busca de compreender a infância no e do campo, como são vistas num contexto caracterizado por intensa dinâmica socioambiental, de classe, econômica, política e cultural. Respaldamo-nos, ainda, nas Diretrizes Curriculares para Educação Infantil que tratam sobre a proposta pedagógica, abordando os modos próprios de vida no campo como sendo fundamentais para a constituição da identidade das crianças moradoras em territórios rurais.

\section{Da educação rural à educação do campo}

\section{Educação rural: histórico de uma política compensatória}

A despeito da identificação de práticas anteriores ao século XX, sobretudo exercidas fora do escopo das políticas públicas, a educação rural, enquanto processo educacional existente no meio agrário brasileiro passa a ser aplicada em maior intensidade somente no limiar do século XX. Ela se refere a uma lista de políticas públicas, como campanhas, programas de alfabetização, dentre outros, praticados pelo Estado brasileiro, sintonizado com os processos de modernização e urbanização do país, tendo como base a educação enquanto justificativa de desenvolvimento para as regiões denominadas mais atrasadas (RODRIGUES, 2006).

Debruçando-se sob o parecer da relatora, Edla de Araújo Lira Soares, aprovado pelo Conselho Nacional de Educação (CNE), do Ministério da Educação (MEC), que aprovou as Diretrizes Operacionais para a Educação Básica nas Escolas do Campo, observaremos sob seu olhar os vários tratamentos que recebeu a educação no meio rural brasileiro, sob a vista das constituições do Brasil. Assim relata que,

\footnotetext{
No Brasil, todas as constituições contemplaram a educação escolar, merecendo especial destaque o tratamento que foi dado ao tema a partir de 1934. Até então, em que pese o Brasil ter sido considerado um país de origem eminentemente agrária, a educação rural não foi sequer mencionada nos textos constitucionais de 1824 e 1891, evidenciando-se, de um lado, o descaso dos dirigentes com a educação do campo e, de outro lado, os resquícios de matrizes culturais vinculadas a uma economia agrária apoiada no latifúndio e no trabalho escravo. (BRASIL, 2002, p. 51).
}

O descaso com a educação no meio rural, nas constituições de 1824 e 1891, não fora minimizado na constituição de 1923 que, a partir do Congresso dos Agricultores do Nordeste, evento que reuniu parte da elite latifundiária no Brasil, a estabelece como um 
ensino meramente técnico. Assim enuncia a relatora sobre as escolas,

Tais instituições, segundo os congressistas seriam destinados aos pobres das regiões rurais e, pasmem, os do mundo urbano, desde que apresentassem pendor para agricultura. [...] A perspectiva salvacionista dos patronatos prestava-se muito bem ao controle que as elites pretendiam exercer sobre os trabalhadores, diante de duas ameaças: quebra da harmonia e ordem das cidades e baixa produtividade do campo. (BRASIL, 2002, p. 54)

Para as constituições que sucederam à de 1923 o tratamento não foi diferente. A situação de não constitucionalidade e o domínio das elites estiveram presentes nas entrelinhas das constituições sobre que tipo de educação deveria estar posta no campo. Sobre as constituições, Fernandes (2002, p. 95) afirma que,

Na constituição de 1934, pela primeira vez aparece uma referência à educação rural que se constituía a partir de um modelo de dominação da elite fundiária. As constituições de 1937 e 1946 evidenciam a mudança de poder da elite agrária para as emergentes elites industriais. Desse modo, mantém-se o modelo de educação rural, mas aperfeiçoa o sistema de subjugação, implantando o ensino agrícola, mais sobre o controle do patronato. [...] A constituição de 1967 e a emenda de 1969, sob o controle ditatorial dos militares, reforçaram esse sistema.

A educação no meio rural, como se observa, nunca foi tratada como um projeto essencial para o desenvolvimento do campo ou mesmo para o homem que vive do campo. A subjugação e o precário modelo educacional ofertado ao camponês, apresentaram-se de forma diferenciada apenas após a nova constituição de 1988. Sob a luz dela, surge a Lei no 9.394/96 da LDB - Lei de Diretriz e Bases -, estabelecendo que,

Na oferta da educação Básica para a população rural, os sistemas de ensino promoverão as adaptações necessárias a sua adequação, as peculiaridades de cada região, especialmente.

I - conteúdos curriculares e metodologias apropriadas às reais necessidades e interesses dos alunos da zona rural;

II - organização escolar própria, incluindo adequação do calendário escolar, as fases do ciclo agrícola e das condições climáticas;

III - adequação à natureza do trabalho na zona rural. (BRASIL, 2002, p. 73)

Deixando um pouco deladoa Constituição de 1988 e a LDB supracitada e voltando-nos para o período anterior, podemos afirmar que a educação existente no meio rural brasileiro, desde os tempos mais antigos, se apresentou como política compensatória. Mesmo o Estado brasileiro reconhecendo as desigualdades de oportunidades tocantes ao desenvolvimento do meio agrário, projetou políticas que se desdobravam no não reconhecimento das diferenciações culturais, econômicas, políticas, sociais e educativas, dentre outras, concomitantes à submissão do campo à cidade. Em outras palavras, a educação no meio agrário brasileiro foi efetivada pelo poder público, com interesses desenvolvimentistas não especificamente para esse setor, e sim para seu atrelamento ao modelo de vida urbano.

Segundo Ricci (1999), dois condicionantes foram fundamentais para que tal situação pudesse ter ocorrido, são eles: um forte pensamento evolucionista que se propagou na grande imprensa brasileira nas primeiras duas décadas deste século e a vertente taylorista de educação, difundida nos EUA. Sobre o primeiro, a autora lembra que a maior representação do camponês, no período, era o personagem Jeca Tatu, criado por Monteiro Lobato, em 1914, em que, não raro, o autor traçava paralelos entre o homem do campo, parasitas e os animais não produtivos (RICCl, 1999). A autora elucida 
esse pensamento evolucionista ao afirmar que:

A sociologia brasileira, nos seus primeiros passos, corroborou a discriminação política e cultural em ralação ao homem do campo. $\mathrm{Na}$ década de 60, Juarez Brandão Lopes, Alain Tourraine, Fernando Henrique Cardoso e Azis Simão sugeriram que a forte presença rural no emergente proletariado fragilizava sua organização e a consciência de classe, facilitando o controle dos sindicatos pelo Estado. (RICCl, 1999, p. 2).

Desta forma, foi estabelecido que o espaço urbano fosse o espaço dos indivíduos mais cultos, evoluídos, além de simbolizar o progresso e de ser sinônimo de desenvolvimento.

Para Ricci (1999), o segundo condicionante que direcionava o entendimento do poder público sobre a escola no meio rural ser fator de compensação e não de reconhecimento da diversidade sociocultural se deu na esteira ideológica que:

foi se projetando uma concepção de escola pública que tinha por objetivo central a formação do trabalhador urbano. E daí nasce a escola pública, taylorista, urbana, para o campo. Uma escola pautada pelo êxodo rural, para a constituição do proletariado urbano. (RICCl, 1999, p. 2).

A educação rural, nesse sentido, fora construída como uma educação, localizada, no campo, uma educação que privilegiou valores estranhos a seu meio e a sua gente, concebendo certo tipo de colonização do camponês.

Rodrigues (2006), ao tentar reconstruir historicamente um pouco da implantação das escolas rurais no Brasil, aponta para o surgimento na década de 1920 do "ruralismo pedagógico", como movimento que:

No campo político-ideológico, trata-se de privilegiar e defender as atividades agrárias como sustentáculo da sociedade brasileira. No campo educacional, trata-se de uma tentativa de mostrar e reforçar valores do sentido rural da civilização brasileira, seu caráter ideológico consistiu em tentar prender o homem ao campo, mesmo contra sua vontade para evitar a migração. (COSTA, 2002 apud RODRIGUES, 2006, p. 3).

O ruralismo pedagógico fora aplicado pelo Estado enquanto política pública nas décadas de 1920 a 1950. No entanto, mesmo se apresentando como projeto sensível aos problemas do homem do campo, por levar em consideração sua condição econômica e tentar evitar sua migração, a conjuntura política das décadas de 1940 e 1950 - em que o processo de industrialização era visto como caminho para o progresso - transformou tal projeto em política assistencialista e preconceituosa ao homem do campo (RODRIGUES, 2006).

Esse pequeno hiato de preocupação e surgimento de uma política voltada para uma educação no meio rural, não foi suficiente para o peso que o Estado brasileiro, no referido período histórico, exercesse decidindo o que era, e qual a serventia de uma política pública educacional voltada para o campo. Dessa forma, consubstanciou-se um olhar sobre a educação rural como sendo uma educação, simplesmente, no campo, uma educação para os atrasados. A educação rural se apresenta, assim, como paradigma do capitalismo agrário que, ao visualizar a extinção do camponês enquanto classe e sujeito histórico, aponta o meio urbano e as relações estabelecidas nele como hegemônicas. O avanço das relações capitalistas no campo, o agronegócio, a agroindústria e todas as formas de territorialização que simbolizam o avanço do capital no campo são compatíveis com a educação rural.

É evidente que o problema da educação brasileira não se resume à educação rural, assim como não se pode compreender que uma mudança de nomenclatura vá modificar uma herança de décadas de marginalização e falta de atenção por parte do Estado brasileiro. 
No primeiro volume da coleção "Por uma educação básica do campo", Molina, Nery e Kolling (1999, p. 44) apontam alguns problemas da escola inserida no meio rural, como:

1. Falta de infraestrutura necessária e de docentes qualificados;

2. Falta de apoio de iniciativas de renovação pedagógica;

3. Currículo e calendário alheios à realidade do campo;

4. Em muitos lugares, atendidas por professores/professoras com visão de mundo urbano, ou com visão de agricultura patronal; na maioria das vezes esses profissionais nunca tiveram uma formação especifica para trabalhar com aquela realidade;

5. Deslocadas das necessidades e das questões do trabalho no campo;

6. Alheia a um projeto de
desenvolvimento;

7. Alienadadointeressedoscamponeses, dos indígenas, dos assalariados do campo;

8. Estimuladora do abandono do campo por apresentar o urbano como superior, moderno, atraente; e,

9. Em muitos casos, trabalhando pela sua própria destruição, é articuladora do deslocamento dos estudantes para estudar na cidade, especialmente por não organizar alternativas de avanço das séries nas escolas do próprio meio rural.

Esses são apenas alguns pontos que podem ser elencados como basilares para superação do modelodeescola presentenocampo, assim como avança no sentido de fazer proposições para sua transformação a partir de políticas públicas que não percebam a escola rural somente enquanto resíduo presente no meio agrário.

\section{O que é educação do campo? Processo ou fim em si mesmo?}

No processo de afirmação e (re)criação do camponês, a partir da luta pelo acesso à terra e pela reforma agrária, a pauta de reivindicação se estende, após a conquista da terra, para outros setores. A educação, nesse estágio da luta, passa a ser alvo de exigências por movimentos sociais camponeses, como o Movimento dos Trabalhadores e Trabalhadoras Sem Terra (MST), por exemplo, que busca promover em seus assentamentos as mais variadas formas de desenvolvimento.

Assim, a educação do campo "nasce como mobilização/pressão de movimentos sociais por uma política educacional para as comunidades camponesas" (CALDART, 2008, p. 71), nasce da combinação das lutas dos sem terra pela implantação de escolas públicas nas áreas de reforma agrária com as lutas de resistências de inúmeras organizações e comunidades camponesas para não perder suas escolas, sua experiência de educação, seu território, sua identidade (CALDART, 2008). Desponta, assim, como educação derivada das reivindicações dos camponeses em luta, assentados que buscam qualidade de vida e desenvolvimento a partir de suas realidades, entendendo o campo como seu lugar de ensino e aprendizagem, em que trabalham, se envolvem e desenvolvem suas relações culturais e educativas.

Contudo, o debate sobre o campo precede a discussão sobre a educação do campo (CALDART, 2008), envolvendo as relações sociais, a cultura, o trabalho camponês, que, fazendo frente ao secular latifúndio brasileiro e às mazelas decorrentes dele, traz a urgência de uma visão que contemple seu desenvolvimento sob a ótica camponesa.

O campo não é só lugar da produção 
agroindustrial, do latifúndio e da grilagem de terras, o campo é lugar de vida, em que se pode trabalhar, morar e estudar. O campo é espaço e território dos camponeses e quilombolas. É no campo que estão as florestas onde vivem as diversas nações indígenas. Por tudo isso, o campo é lugar de vida e, sobretudo de educação (FERNANDES, 2002).

No entanto, podemos compreender que há um conflito latente hoje no meio agrário brasileiro, advindo da proposta de dois modelos de desenvolvimento rural, um sobre o enfoque neoliberal, outro sobre a perspectiva dos movimentos sociais. Assim, dois territórios se apresentam como lócus da produção e reproduçãodessesmodelosoterritóriocamponês e o território capitalista (MARCOS, 2006).

A educação do campo - entendida aqui como uma educação que privilegia a realidade camponesa - prioriza suas realidades, não se submetendo à hierarquia do conhecimento urbano e a sua hegemonia nos livros didáticos, assenta-se sobre o território camponês, buscando apresentar a dicotomia campo-cidade, sob a perspectiva do campo, lutando pela afirmação e preservação da identidade camponesa.

Para Fernandes (2002, p. 97) a educação do campo se apresenta como um conceito

cunhado com a preocupação de se delimitar um território teórico. Nosso pensamento é defender um direito que uma população tem de pensar o mundo a partir do lugar onde vive, ou seja, da terra que pisa, melhor ainda: desde a sua realidade. Quando pensamos o mundo a partir do lugar onde não vivemos, idealizamos um mundo, vivemos um não lugar. Isso acontece com a população do campo quando pensa o mundo e, evidentemente, o seu próprio lugar a partir da cidade.

Grosso modo, podemos concluir previamente que há uma identidade sendo construída no campo, uma identidade que envolve a luta pela educação, uma educação que possibilite a afirmação dos sujeitos, presente no campo e sua reprodução. Uma identidade que, segundo Caldart (2002, p. 26), fortaleça o direito a educação no e do campo, "NO: o povo tem o direito de ser educado no local onde vive. DO: o povo tem direito a uma educação pensada desde o seu lugar e com a sua participação, vinculado a sua cultura e a suas necessidades humanas e sociais".

Essa dimensão apresentada por Caldart (2002) provoca a reflexão sobre a antiga e, infelizmente, ainda presente compreensão de que a educação inserida no meio rural não era/é nada mais que uma educação realizada em um local distante e diferente da cidade, denominada assim de educação rural. Dito de outra forma, a autora reflete sobre um modelo de educação que não esteja limitado à antiga conceituação de educação rural, como a educação para o campo, o que não, necessariamente, significaria uma educação voltada à realidade camponesa.

É também, nesse sentido, que Molina, Nery e Kolling (1999), no primeiro volume da série de cadernos intitulada Por uma educação do campo, de 1999, propõem a utilização da expressão "campo" no lugar de "meio rural" para mudança de concepção que se tinha/tem sobre a educação no meio agrário, assim como do envolvimento desta com os trabalhadores do campo. Nessa esteira, os autores afirmam que,

quando se discutir a educação do campo, se estará tratando da educação que se volta ao conjunto dos trabalhadores e trabalhadoras do campo, sejam os camponeses, incluindo os quilombolas, sejam as nações indígenas, sejam os diversos tipos de assalariados vinculados ao trabalho e vida no meio rural. (MOLINA; NERY; KOLLING, 1999, p. 26).

Como proposta para superação deste paradigma, de educação rural para educação do e no campo, Fernandes (2006, p. 3) corrobora, atribuindo à educação do campo,

a política educacional votada para o 
desenvolvimento do território camponês como parte do campo brasileiro. Este território é um campo específico e diverso que possui singularidade na sua organização por meio do trabalho familiar. Portanto, não estamos falando de um campo genérico, mas sim de um Campo como território camponês. Daí, a ênfase na contração do Campo. Porque o Campo é ponto de partida e de chegada de nossas analises. Não é no Campo, porque o território não é secundário.

Embora divergindo de Caldart (2002), na substituição da contração no pelo do, Fernandes (2005) contempla a discussão sobre a necessidade de uma educação diferenciada do homem do campo, a partir da especificidade do território camponês, avançando assim para concepção de educação do e não reduzida para ou no campo. Sob essa ótica, ao contemplar além do território camponês, a educação do campo estende-se a seus sujeitos que se apresentam, sejam como profissionais da educação professores, coordenadores pedagógicos etc. -, sejam como alunos - agricultores familiares, sem terras, filhos de trabalhadores e trabalhadoras do campo, dentre outros. A educação do campo, dessa forma, se apresenta como processo e não como fim. Processo, por proporcionar a reprodução do camponês enquanto sujeito, que se reconhece na escola, nas didáticas e nas pedagogias, sensíveis a seu território específico, o campo.

Por não ser um fim em si mesma, a educação do campo possibilita o resgate de valores culturais, sociais e políticos do camponês, cultivando, nos mais jovens, seu modo de vida, suas relações com a terra, com a água e com o meio ambiente. É processo que, associado à luta pela reforma agrária, seja em assentamentos ou acampamentos, territorializa o camponês.

Uma educação do campo que se volte para a realidade e os anseios do camponês precisa ser, sob olhar de Freire (1978), orientada para o desenvolvimento da consciência social.
Nesse prisma, a escola se apresenta no âmago para o seu desabrochar.

\section{Por uma escola do campo!}

Após breve conceituação sobre a educação do campo, fica a pergunta: Onde ela pode se materializar? Respondemos: na escola do campo. Não somente sobre um olhar simplório que a perceba como local para escolarização ou alfabetização, mas que se estenda para o entendimento que prove que ela seja apresentada como o ambiente adequado para concretização da concepção que temos tratado.

Contudo, alertamos que essa visão não busca se limitar a ser uma proposta que centralize toda a construção social da concepção de educação do campo, findando em uma única instituição, na qual o processo de ensino aprendizagem se formalizou, a escola. Para a educação do campo, o sentido de escola é bem mais amplo, representa o contato do camponês com o seu saber, com sua vivência. Nesse prisma, Fernandes (1999, p. 65) indica a escola ser

aquela que defende os interesses, a política, a cultura e a economia da agricultura camponesa, que construa conhecimento e tecnologias na direção do desenvolvimento social e econômico desta população. A sua localização é secundária, o que importa são suas proximidades política e espacial com a realidade camponesa.

Nesse sentido, Caldart (2002, p. 34) contribui para essa afirmação, justificando que "construir uma escola do campo, significa estudar para viver do campo, ou seja, inverter a lógica de que se estuda para sair do campo". A escola deve proporcionar orgulho para aqueles que a frequentam, não deve ser motivo de frustração ou imposição. A escola do campo deve fortalecer a identidade do camponês e 
projetar sua identificação, seu reconhecimento, seja pelo lado individual, enquanto sujeito, como do coletivo, enquanto classe.

Institucionalmente, essa compreensão é contemplada pelas Diretrizes Operacionais para Educação Básica das Escolas do Campo, sendo fruto da luta dos movimentos sociais presente no campo, mais bem explicada no tópico "Histórico das diretrizes" deste capítulo, que reconhecem a escola do campo e, sua particularidade, consequente de seus sujeitos. Assim, o parágrafo único do Art. $2^{\circ}$, enuncia que,

A identidade da escola do campo é definida pela vinculação a questões inerentes a sua realidade, ancorando-se na temporalidade e saberes próprios dos estudantes, na memória coletiva que sinaliza futuros, na rede de ciência e tecnologia disponível na sociedade e nos movimentos sociais em defesa de projetos que associem as soluções exigidas por essas questões à qualidade social da vida coletiva do país. (BRASIL, 2001 apud FERNANDES, 2002, p. 99).

Todavia, no Brasil, contribuem também para essa identidade os problemas existentes no meio agrário. O latifúndio, a falta de políticas públicas para a pequena agricultura, o êxodo rural, dentre outras questões, são problemáticas que precisam ecoar sob os muros da escola camponesa, não no sentido de provocar desestímulo e renúncia ao mundo rural, mas provocar o embate e o confronto dos sujeitos do campo com sua realidade.

No bojo dessa discussão, assim como no debate sobre a diferença entre educação $d o$ e no campo, também se apresenta a proposta de substituição das contrações, para justificar e defender um modelo de educação que esteja coerente com a realidade do camponês e supere seu antigo formato, da escola rural.

As diferenças que sintetizam os modelos de educação do campo para educação no campo - ou melhor, educação do campo para educação rural - são bem explicitados por Fernandes (2002) ao indicar que a escola no campo representa um modelo pedagógico ligado a uma tradição ruralista de dominação, enquanto a escola do campo representa a proposta de construção de uma pedagogia, tomando como referência as diferentes experiências de seus sujeitos, os povos do campo.

Diante do que foi exposto, apresentamos a definição de escola do campo, contido no primeiro volume dos cadernos que compõem a coleção Por uma educação básica do campo, nele a escola é salientada como aquela que

\begin{abstract}
trabalha desde os interesses, a política, a cultura, e a economia dos diversos grupos de trabalhadores e trabalhadoras do campo, nas suas diversas formas de trabalho e de organização, na sua dimensão de permanente processo, produzindo valores, conhecimentos e tecnologia na perspectiva do desenvolvimento social e econômico igualitário dessa população. A identificação política e a inserção geográfica na realidade cultural do campo são condições fundamentais de sua implementação. (MOLINA; NERY; KOLLING, 1999, p. 63).
\end{abstract}

Decerto, devemos ter em mente que a escola do campo pressupõe uma pedagogia própria ancorada ao seu modo de vida, exige educadores e educadoras do campo, comprometidos/as com a realidade rural, incluindoa participação da comunidadenagestão da escola que, por ser democrática, deve assumir questões e discussões presentes no meio agrário.

\section{Breve histórico da educação infantil do campo}

Sabemos que a história da educação infantil brasileira foi se constituindo, ao longo dos anos, com base nas situações sociais de cada contexto histórico. Durante grande parte do tempo, a realidade das crianças presentes no meio rural, olvidadas de seu direito à educação, girava em torno do entendimento de seus pais 
ou responsáveis de que elas deveriam realizar trabalhos domésticos e do campo, ocasionando a inserção desses pequenos precocemente nas atividades laborais identificadas como do ser adulto, e, dessa forma, o excluindo de vivenciar os benefícios que a infância pode promover em variados processos de desenvolvimento pessoal, como o cognitivo, por exemplo.

Cabe lembrar, que a história da educação infantil possui uma trajetória conjunta ao surgimento das primeiras instituições de ensino, estando, no momento indicado, abrigadas sob o viés do pensamento pedagógico moderno. Esse processo se deu por consequência de mudanças de compreensão social advindas de uma racionalidade modelada na Europa, contrastando com o pensamento vigente até meados do século XIX, em que não havia o entendimento sobre a necessidade de instituições atenderem crianças em seus ambientes educativos. Como dito, esse sistema sofreu modificações a partir da segunda metade do século XIX, quando surgiu o período de abolição da escravatura no país, o que provocou mudanças substanciais na realidade brasileira, dentre elas, o aumento populacional nas zonas urbanas em decorrência da migração oriunda da zona rural. Com a notória concentração urbana e, ainda, antecedendo a proclamação da República, instituições destinadas ao atendimento e assistência social a crianças ocorre, porém, de forma isolada. Como parte desse momento, podemos citar a criação de entidades de amparo, asilos, internatos e creches destinadas a cuidar das crianças mais pobres.

Com o surto da urbanização e industrialização no início do século XX, houve uma modificação na estrutura familiar, pois as mães precisavam trabalhar nas fábricas, ficando as crianças aos cuidados de outras pessoas. Aos poucos foram ocorrendo conquistas por instalações de creches no setor industrial, como afirma Oliveira (2011, p. 101), “a preocupação que se tinha com as crianças era de cuidar da higiene da segurança física e alimentação, sendo pouca a preocupação de um trabalho destinado à educação e ao desenvolvimento psicológico da criança pequena".

Contudo, novas perspectivas surgiram no sentido de mudanças desse quadro, e novas atenções voltadas para os aspectos cognitivos da criança passam a ser discutidas. No limiar da década de 1980, foram feitos muitos questionamentos a respeito do trabalho pedagógico em que os professores abordavam que as crianças das classes menos favorecidas não estavam sendo incluídas no quadro das ações pedagógicas.

No que concerne à educação infantil do campo, no final dos anos 1990, a ação feminista articulada com a de sindicalistas na Confederação Nacional de Trabalhadores de Educação (CNTE), conseguiu redigir na Lei de Diretrizes e Bases (LDB/1996) a ideia de creche como espaço de cuidado e educação (BRASIL, 2014). Vale ressaltar ainda que o Ministério da Educação (MEC) realizou uma série de iniciativas direcionadas à educação infantil do campo e à sua institucionalização na agenda política nacional, dentre as quais o I Seminário Nacional sobre Educação Infantil do Campo, ocorrido em 2010, em Brasília, com a participação de diversos segmentos sociais. Destacamos que, dentre as recomendações propostas, segundo o Grupo de Trabalho Interinstitucional (GTI) estabelecido pela Portaria no 6/2013, algumas versaram sobre a importância e incentivo a indução do diálogo intersetorial e a realização de pesquisas nacionais sobre as condições da oferta e demanda da Educação Infantil, a fim de subsidiar ações governamentais. A partir dos seminários, estudos e pesquisas direcionadas para essa modalidade da educação básica, a educação infantil apresentou-se como importante demanda apresentada aos movimentos sociais e sindicais do campo, bem como às mulheres, destacandose a relação direta entre a primeira infância e os 
cuidados atribuídos a elas na nossa sociedade. Conforme o Grupo de Trabalho Interministerial (2014, p. 9),

Compreender a histórica reivindicação das mulheres, por direitos e autonomia, aliada ao tema da socialização dos cuidados entre família, o Estado e a Sociedade significa que, ao se construir perspectivas para uma Educação Infantil do Campo, com qualidade, deve-se desconstruir a imagem idealizada de que a mulher é a única responsável pelo ato de "cuidar e educar", na primeira infância.

Nesse sentido, a reivindicação de escolas de educação infantil localizadas nas áreas rurais implica, na realidade, em direito de mulheres e de crianças, em virtude daquelas participarem da vida social e econômica, bem como desempenharem maior protagonismo no mundo do trabalho, pela possibilidade de desenvolvimento de atividades geradoras de renda.

Ainda, seguindo o Grupo de Trabalho Interministerial (2014, p. 10),

Como passo importante para garantir o acesso à Educação Infantil e autonomia econômica das mulheres, a pauta da Marcha das Margaridas de 2011 trouxe a reivindicação do atendimento às filhos e filhas das mulheres trabalhadoras do campo em período integral em creches e pré-escolas de educação infantil. Reivindicava-se a ampliação da oferta de Educação Infantil, com vista à sua universalização conforme preceitua a Resolução CNE/CEB n02/2008 e o Decreto presidencial no 7532/2010 e a importância de se construir escolas nas próprias comunidades rurais, principalmente para a educação infantil e anos inicias do ensino fundamental, evitando-se assim, o transporte escolar para crianças pequenas.

Diante do exposto, vimos que a reivindicação tinha como finalidade a implantação de creches em tempo integral, levando em consideração os contextos e as especificidades das crianças que estão inseridas no campo, haja vista que a educação infantil vem paulatinamente se consolidando como uma área própria de conhecimentos, saberes específicos, no diálogo e na articulação com os outros níveis de educação. Todavia existem desafios que precisam ser enfrentados para sua efetivação. Um deles se refere às crianças que moram em áreas rurais, ou seja, filhos de agricultores, ribeirinhos, assentados, dentre outros povos que habitam o território campesino, tendo em vista a importância de a educação ser realizada o mais próximo do lugar de residência das crianças.

É também nesses termos que Silva e Pasuch (2012) indicam que a construção da Educação Infantil do campo requer, portanto, movimentos de aproximações e diferenciação, tanto em direção ao acúmulo da Educação Infantil como em direção ao acúmulo da educação das populações do campo, no marco das discussões mais amplas de educação e de projeto de sociedade. Requer também que cada área esteja disposta à criação de um campo dialógico, o que necessariamente implica:

a. Reorganizar perspectivas e pontos de vista pessoais e institucionais;

b. Pautar e problematizar, a partir dos movimentos sociais e sindicais do campo e da infância, a questão da educação coletiva das crianças de zero a seis anos de idade do campo;

c. Repensar a organização política da Educação Infantil e da Educação do Campo nos sistemas nacional, estadual e municipal de Educação;

d. Reorganizar estratégias de formação de professores/as. (SILVA; PASUCH, 2012, p. 83). 
Verificamos, a partir desse enunciado, a importância da educação infantil do campo para as crianças que estão na faixa etária de até cinco anos de idade conforme o Art. 30 da LDB no 9.394/96, bem como, sua consonância com a Emenda Constitucional número 59. Ambas se referem às questões do direito à creche/ pré-escola, para essa faixa etária, incluindo dessa forma a Educação Infantil do Campo, com sua especificidade de organização advinda do contexto familiar e coletivo, além disso, considerando os saberes interdisciplinares dos povos campesinos.

Nesses termos, podemos constatar quanto os sujeitos envolvidos na educação do campo constroem suas sociabilidades, subjetividades, e, sobretudo, suas identidades. Seguimos, assim, evidenciando a necessidade do reforço sobre as reflexões e práticas sobre a educação dos povos no campo, reconhecendo como ela é plural e diversa, seja pelas diferentes formas de organização familiar, como também pela constatação das visíveis formas de (re)existir desses sujeitos em suas etapas de desenvolvimento cognitivo.

\section{Considerações para o debate}

Diferente da educação do campo, a educação rural se constituiu como política compensatória, já que segundo sua ótica o camponês está em extinção; sua preocupação única é possibilitar às populações camponesas sua integração a lógica urbana. O modo de vida, as realidades e as diversidades culturais dos camponeses, não são consideradas. A educação rural se constitui como uma educação que não entende os camponeses como sujeitos. A reprodução do modo de vida urbano se estende ao campo, em que os camponeses estão subalternos às dinâmicas do modo de produção do capital.

Nesse debate, se faz importante compreender que a educação infantil do campo só se faz possível com a efetivação de uma educação do campo que compreenda as especificidades desses sujeitos a partir de sua plena participação, considerando seus anseios e suas identidades, em um processo de elaboração coletiva. A escola se apresenta não só como o espaço físico, mas como a concretização de um projeto educacional coerente com a demanda e a realidade de seus moradores da infância à fase adulta.

Nesses termos, devemos considerar também que a educação infantil do campo não deve se restringir a ser um fim em si mesma, fechando ou impedindo os sujeitos envolvidos no seu processo do diálogo com o meio urbano ou outros espaços e seus modos de vida. Pelo contrário, deve ser construída em diálogo

permanente e cuidadoso, considerando as lógicas e os elementos característicos advindos das relações sociais dessas populações, assim como de outras comunidades tradicionais.

\section{Referências}

BRASIL. Lei de Diretrizes e Bases da Educação Nacional. Lei no 9.394, de 20 de dezembro de 1996. Estabelece as diretrizes e bases da educação nacional. Brasília, DF, 1996.

. Ministério da Educação. Conselho Nacional de Educação. Parecer CNE/CEB no 36/2001.

Diretrizes Operacionais para a Educação Básica nas Escolas do Campo. Brasília: MEC/CNE, 2001. 
. Ministério da Educação. Portaria Interministerial no 6, de 16 de maio de 2013. Institui o grupo de trabalho interinstitucional para a educação infantil no campo. Brasília, DF, 2013.

. Ministério da Educação. Secretaria de Educação Básica. Diretrizes Curriculares Nacionais para a Educação Infantil. Brasília: MEC, SEB, 2010.

CALDART, R. S. Educação em movimento: formação de educadoras e educadores do MST. Petrópolis, RJ: Vozes, 1997. 180 p.

. Por uma educação do campo: traços de uma identidade. In: CALDART, R. S., CERIOLI, P. R., KOLLING, E. J. (Org.). Educação do campo: identidade e políticas públicas. Brasília: Articulação Nacional "Por uma Educação Básica do Campo, 2002. p. 25-36. (Coleção por uma educação do campo; n. 4).

. Sobre educação do campo. In: SANTOS, C. A. (Org.). Educação do campo: campo, políticas públicas, educação. Brasília: INCRA: MDA, 2008. p. 67-86.

FERNANDES, B. M. Diretrizes de uma caminhada. In: CALDART, R. S., CERIOLI, P. R., KOLLING, E. J. (Org.). Educação do campo: identidade e políticas públicas. Brasília: Articulação Nacional "Por Uma Educação Básica do Campo", 2002. p. 89-101. (Coleção por uma educação do campo; n. 4).

. Educação do campo e território camponês no Brasil. In: SANTOS, C. A. (Org.). Educação do campo: campo, políticas públicas, educação. Brasília: Incra; MDA, 2008. p. 39-66.

. Os campos da pesquisa em educação do campo: espaços e territórios como categorias essenciais. In: MOLINA, M. C. Educação do campo e pesquisa: questões para reflexão. Brasília: MDA, 2006.

Por uma educação do campo. In: ARROYO, M. G., FERNANDES, B. M. A educação básica e o movimento social do campo. Brasília, DF: Articulação Nacional "Por uma Educação Básica do Campo", 1999. p. 53-70. (Coleção por uma educação do campo; n. 2).

FREIRE, P. Ação cultural para a liberdade. 3. ed. Rio de Janeiro: Paz e Terra, 1978. 245 p.

MOLINA, M. C., NERY, I.; KOOLLING, E. J., (Org.) Por uma educação básica do campo: memória. [S.I.: s.n.], 1999. 98 p. (Coleção por uma educação do campo; n. 1).

MARCOS, V. de. Tempo de semear: novos caminhos para um novo campo no Brasil do século XXI. In: SILVA, J. B. da.; LIMA, L. C.; ELIAS, D. (Org.). Panorama da Geografia Brasileira 1. São Paulo: Annablume, 2006, p. 203-220.

MARTINS, F. J. Formação continuada de professores, MST e escola do campo. In: (Org.). Educação do campo e formação continuada de professores. Porto Alegre: EST edições, 2008. p. 30-53.

OLIVEIRA, Z. de M. R. de. Educação infantil: fundamentos e métodos. 7. ed. São Paulo: Cortez, 2011. 264 p. Doi: https://doi.org/10.5902/198464442915.

OLIVEIRA, A. U. A agricultura camponesa no Brasil. São Paulo: Contexto, 2002. 164 p. 
ROCHA, M. I. A. Prefácio. In: SILVA, A. P. S. da; MARTINS, A. A.; SILVA, I. de O. (Org.). Infâncias do campo. Belo Horizonte: Autêntica, 2013. p. 9-11.

RODRIGUES, S. J. D.; NASCIMENTO, R. C. G.; RODRIGUES, U. M. Da educação rural à educação do campo: uma análise da trajetória conceitual. 2006. (impresso)

SILVA, A. P. S.; PASUCH, J.; SILVA, J. B. Educação infantil do campo. São Paulo: Cortez, 2012. 272 p.

Submetido em 11 de julho de 2018.

Aprovado em 13 de setembro de 2018. 